This is a self-archived version of an original article. This version may differ from the original in pagination and typographic details.

Author(s): Saarinen, Jussi A.

Title: What can the concept of affective scaffolding do for us?

Year: 2020

Version: Submitted version (Preprint)

Copyright: (c) 2020 Informa UK Limited

Rights: In Copyright

Rights url: http://rightsstatements.org/page/lnC/1.0/?language=en

Please cite the original version:

Saarinen, J. A. (2020). What can the concept of affective scaffolding do for us?. Philosophical Psychology, 33(6), 820-839. https://doi.org/10.1080/09515089.2020.1761542 
(This is a pre-refereed version of the article. For the published version, please visit

Philosophical Psychology, https://doi.org/10.1080/09515089.2020.1761542)

\title{
What can the concept of affective scaffolding do for us?
}

\author{
Jussi A. Saarinen
}

\begin{abstract}
The concept of affective scaffolding designates the various ways in which we manipulate the environment to influence our affective lives. In this article, I present a constructive critique of recent discussion on affective scaffolding. In Part 1, I summarize how the theories of situated mind and niche construction contribute to a multidimensional notion of scaffolding. In Part 2, I focus specifically on affective scaffolding and argue that current ambiguity over its distinctive criteria causes uncertainty as to how the concept can and should be used. In Part 3, I identify and examine two possible responses to the suggested state of conceptual ambiguity. The first, restrictive option is to keep pushing for more definite criteria. The second, permissive option is to embrace and work with a broad understanding of affective scaffolding. I argue that the latter choice is more pragmatic and productive. To conclude, I summarize where my examination leaves us in regard to ongoing theoretical work on affective scaffolding.
\end{abstract}

Keywords: affective scaffolding, affectivity, situated mind, scaffolded mind, niche construction

\section{Introduction}

We humans continuously interact with the world in order to influence the way we feel. We seek the company of others to lift our spirits, use highly sophisticated streaming devices for entertainment and pleasure, and spare no effort in creating art - just for the sheer contentment of it. Such manipulation of the environment for affective effects has been designated in recent philosophy of mind as affective scaffolding (Colombetti \& Krueger, 2015; Colombetti, 2017b; Maiese, 2016; Saarinen, in press; Slaby, 2016). This serves to highlight the fact that our affective states are frequently enabled, supported, and regulated by environmental elements such as physical objects and other people. In a broader philosophical framework, the concept of affective scaffolding challenges the internalist assumption that emotions, moods, and other feelings supervene solely on intra-individual states and processes. Its proponents have thus redirected attention from predominantly brain-centric explanations of affectivity to ones that acknowledge the dependence of affective states on the material and social contexts in which they occur. All in all, the notion of affective scaffolding is making an 
increasing impact on affectivity research and the internalism vs. externalism debate, and thus merits continuing scrutiny.

Despite its growth in visibility and importance, theorization on affective scaffolding (henceforth TAS) is still in an emergent phase. In this article, I present a constructive critique of TAS and map out paths for its further refinement. In Part 1, I summarize how the principal sources of TAS, namely, the theories of situated mind and niche construction, contribute to the concept of scaffolding. I also review the various dimensions along which the scaffolded mind has thus far been analyzed. The purpose of this is to demonstrate that, as multidimensional phenomena, scaffolding interactions are seen to occur in a wide variety of forms. Moreover, it is within this basic framework that I discuss TAS critically.

In Part 2, I move on to scrutinize affective scaffolding in specific and, with the help of examples given by its advocates, investigate its current conceptual boundaries. I focus on two interrelated issues, namely, the ways in which both active environmental modification and mutual influence between agent and environment are presumed to underlie affective scaffolding. Based on this, I argue that there is an unaddressed concern at the heart of TAS. That is, despite conjecture about the essential features of affective scaffolding, these have not been developed into properly distinctive criteria in any systematic fashion. The upshot of this is that, if we expect the concept of affective scaffolding to distinguish clearly between scaffolded and non-scaffolded affects, it currently falls short due to its indefiniteness. It also appears to be problematically inclusive, as it seems to inadvertently accommodate too many, if not indeed most, affective states within the category of scaffolded affects. In sum, there is a lingering uncertainty over what we can and should expect the concept of affective scaffolding to do for us.

In Part 3, I identify and discuss two possible responses to the present state of conceptual ambiguity. The first, restrictive option is to keep pushing for more definite criteria for affective scaffolding. This option presupposes that the concept of affective scaffolding should, by its very nature, enable a clear distinction between scaffolded and non-scaffolded affects. The second, permissive option is to embrace - rather than problematize - a broad and inclusive understanding of affective scaffolding. On this view, the term scaffolding would not primarily be expected to do distinctive work but would instead be used to identify and elaborate on a perpetual feature of affective experience. I submit that, all things considered, the second choice is more pragmatic and productive. To conclude, I summarize where my examination leaves us in regard to ongoing theoretical work on affective scaffolding.

\section{Situatedness, niche construction, and the scaffolded mind}

TAS is premised on the mind's situatedness. This means that mental activity is fundamentally co-determined by the context in which it occurs (see e.g. Griffiths \& Scarantino, 2009; Robbins \& Aydede, 2009; Slaby, Mühlhoff, \& Wüschner, 2017; Stephan, Walter, \& Wilutzky, 2014; Wilson \& Clark, 2009). On the situated view, then, the environment plays an 
active and decisive role in supporting mental processes. This is in direct opposition to regarding the environment as a mere background source of inputs for presumably intracranial mental states. The technical term scaffolding has accordingly been adopted to designate the various ways in which environmental elements support, regulate, augment, and enhance our cognitions, affects, or actions (see e.g. Clark, 1997; Colombetti, 2017b; Colombetti \& Krueger, 2015; Sterelny, 2010; Sutton, 2016). ${ }^{1}$ Importantly, scaffoldings are structured and employed through our active engagements with the world. In this way, the situated approach underscores perpetual agent-environment interactions in accounting for the life of the mind.

Proponents of TAS have also drawn on the biological theory of niche construction to further the situated view (see e.g. Colombetti \& Krueger, 2015). Put broadly, niche construction refers to activities and processes whereby organisms modify their selective environments in ways that affect their own behavior and evolutionary fitness, and often those of future generations and other species as well (Odling-Smee, Laland, \& Feldman, 2003; Laland, Matthews, \& Feldman, 2016; for a critical appraisal, see Scott-Phillips, Laland, Shuker, Dickins, \& West, 2014). For example, earthworms alter the structure and chemistry of the soil they live in in ways that sustain their existence in that very habitat. In this manner, the worms' construction of an environmental niche feeds back onto the worms (and other organisms) to increase their chances of survival. ${ }^{2}$ In philosophy of mind, the concept of niche construction has been applied similarly to examine the various processes whereby humans manipulate the material, social, epistemic, and cultural environment to support and enhance their psychological and experiential capabilities (see Clark, 2006; Colombetti \& Krueger, 2015; Sterelny, 2010; Sutton, Harris, Keil, \& Barnier, 2010). Like the situated approach, niche construction emphasizes our own activeness in influencing how we come to think and feel. This amounts to the core idea that we build niches to scaffold our minds.

Researchers of the scaffolded mind have examined the nature of niches and their scaffolding functions along several interrelated dimensions. First of all, attention has been called to the environmental elements of niches, that is, to the types of resources that are modified and used for scaffolding purposes. A distinction has been made, for instance, between material and social resources (Krueger, 2018; Sutton, 2016). The former encompass the inanimate world of artefacts, tools, spaces, places, and so on. The latter refer mainly to interactions with other people, be they individuals, groups, or collectives. In reality, niches can be composed of both types of resources and, in fact, of other types that do not fit neatly under either. Consider how joint online gaming scaffolds experience. It consists in ongoing interaction with a complex set of material and social resources - not to speak of the various norms, rituals, symbolic systems, and linguistic practices at play. Arguably, these are all relevant contributing elements of the overall gaming niche.

\footnotetext{
${ }^{1}$ For a helpful overview of the history and uses of the term "scaffolding" in developmental psychology, educational theory, and cognitive science, see Pea, 2004, and Sutton, 2016.

2 Besides this type of "perturbational" niche construction, organisms also exhibit "relocational" niche construction when they expose themselves to novel selective environments via migration, habitat selection, and dispersal (Laland, Matthews, \& Feldman, 2016).
} 
Second, niches have been suggested to exert their influence on various timescales (Colombetti \& Krueger, 2015; Griffiths \& Scarantino, 2009; Sutton, 2016). On the one hand, scaffoldings can be synchronic. In this case, mental activity is enabled and supported by real-time interaction between the agent and the resource. A straightforward example of this would be listening to music to regulate one's ongoing feelings. On the other hand, scaffoldings can be diachronic and function over extended periods of time. For instance, technological expertise has been developed, organized, and passed down through generations to enhance our minds' capacities. In this sense, we do not merely set up and use niches for short-term individual purposes; we are also influenced by already existing, collectively sustained niches. The effects of such long-term niches may be assessed, for instance, on phylogenetic, cultural-historical, and ontogenic timelines (Sutton, 2016).

Third, niches have been analyzed in regard to their primary domains of influence, that is, in terms of the particular capacities and experiences they are taken to scaffold (Krueger, 2014a; Sutton, 2016). In general, cognitive niche construction consists in developing and using environmental resources to support learning, reasoning, problem solving, decision-making, memory, and so on. Affective niche construction in turn deploys environmental modification to scaffold emotions, moods, bodily affective styles, background feelings, and the like. However, niches need not be strictly cognitive or affective. They may, and often do, scaffold both domains simultaneously and to varying extents (see e.g. Maiese, 2016). Even so, the distinction is useful in analyzing the cognitive/affective aspects of scaffolding and in identifying which of the two, if either, is intended as the primary target of influence in any given niche.

Together the three discussed dimensions - structure, timescale, and domain provide a general descriptive framework for the functioning of niches. By homing in on actual agent-resource interactions, theorists have identified further variable features of scaffolding situations (Colombetti \& Krueger, 2015; Sterelny, 2010; Heersmink \& Sutton, 2018). One such variable is the degree to which a given instance of scaffolding involves causal reciprocality or mutual influence between the agent and the relevant resource (Colombetti \& Krueger, 2015; Krueger, 2018; Heersmink \& Sutton, 2018). Sometimes resources operate more or less one-directionally to scaffold the mind, like when one relies on a printed map to support navigation. In other cases, the resource becomes a more integrated part of the activity or task at hand and tends to be much more amenable and responsive to the agent's actions. When an improvising musician produces music that affects the way she feels, and when this in turn influences what she plays next, her ongoing affective experience is scaffolded by the music in truly bi-directional fashion (Krueger \& Szanto, 2016, p. 867).

In addition to reciprocality, scaffolding situations differ in their individuality vs. collectivity (Colombetti \& Krueger, 2015; Sterelny, 2010). On one end of the spectrum we find individual agents interacting with singular resources, like when a student writes down information for later personal recall. On the other, we have situations where multiple agents interact jointly within collectively structured niches. Increasingly, on-field soccer referees do not only depend on each other to officiate a match, but also on off-field referees assisted by highly sophisticated video equipment. In this way, making the correct decisions about goals, 
penalties, and red cards is supported by collaborative interaction with collectively organized technological resources.

There is also variation in the degree to which a given resource is individualized (Colombetti \& Krueger, 2015; Sterelny, 2010). Consider any ordinary calculator. It will perform its job reliably and predictably, and can thus be substituted with a comparable standard unit without significantly affecting the scaffolded task. Other resources, however, tend to become adapted and tailored specifically to the agent's personal purposes and regular activities. This is aptly illustrated by the relationships professionals and skilled experts develop with their tools, typically over longer periods of time. Chefs customize and adapt to their knives, cyclists overhaul and fix up their bikes, and drummers configure their kits to suit their personal needs and habits. Replacing these highly individualized resources with similar yet standard ones is likely to alter the agent's scaffolded capacity, activity, or experience. On a related note, resources sometimes become experienced as deeply ingrained parts of oneself and one's activities. The blind person's use of a white cane is a prime example of such entrenchment of a resource (Colombetti \& Krueger, 2015, p. 1161; see Merleau-Ponty, 1962). Through practice, the cane is fused into the agent's corporeal schema and is ultimately passed over as an intentional object of attention.

Theorists have also examined the level of trust involved in scaffolding interactions (Colombetti \& Krueger, 2015; Sterelny, 2010). Here trust refers to the perceived reliability of a given resource in supporting particular activities or bringing about certain effects. For example, in making diagnoses, doctors presumably have a high degree of trust in the proper functioning of MRI scans and in the information that these provide. Trust can also develop into outright dependency. Consider again the professional musician and her instrument. Over time, playing the instrument can become such a deeply trusted and entrenched part of the musician's affective-expressive repertoire that losing access to it amounts to an inability to feel certain emotions and moods (Colombetti \& Krueger, 2015, p. 1164).

Finally, it has been suggested that modifying the mind via scaffolding does not necessarily require conscious intent on the agent's part (Colombetti \& Krueger, 2015; Slaby, 2016). We often interact with the environment in habitual, non-reflexive ways, and this is seen to apply to scaffolding interactions as well. One may, for example, go through a fixed cycle of morning routines that involve adjustments to ambiance, intake of stimulants, and various types of grooming - just to get in the right mood for the day. Furthermore, it has been suggested that our minds can be scaffolded via others' intentions and actions as well (Krueger, forthcoming; Slaby, 2016). This may even occur against our personal wishes and beyond our individual control. For instance, the demand for constant accessibility via mobile technology can compel us to feel excessively connected to work (Slaby, 2016, p. 10). In short, whether we are aware of it and whether we consent, niches are set up by others to influence the way we think and feel. Viewed in this light, affective scaffolding is a more perpetual phenomenon than might initially seem. 
To sum up the above, any instance of scaffolding can be analyzed along the dimensions of structure, temporality, domain, reciprocality, trust, individuality/collectivity, individualization/entrenchment, and intent. With the help of these dimensions, we can specify the ways in which the concept of scaffolding can be applied from case to case. To be clear, I do not suggest that the given listing covers all pertinent aspects of the matter. The primary purpose of this overview has instead been to demonstrate that, in light of current theorization, the scaffolded mind is a multidimensional phenomenon and that scaffolding interactions accordingly come in a wide variety of forms. It is within this basic framework that I next discuss affective scaffolding in more detail.

However, before doing so, one final note on the philosophical links of TAS is in order. As mentioned, the development of TAS has been strongly informed by externalist thinking. It therefore aims to replace accounts of mind that focus on internal organismic mechanisms with explanations that underline integrated organism-environment couplings and interactions (Colombetti \& Krueger, 2015). This view has motivated several scholars to advance the notion of extended affectivity, which holds that elements of the environment can become ontologically constitutive parts of affective states (for further discussion, see Colombetti, 2017a; Colombetti \& Roberts, 2015; Krueger, 2014; Krueger \& Szanto, 2016; Maiese, 2016; Slaby, 2014b; Stephan, Walter, \& Wilutzky, 2014; Sterelny, 2010). The difference between scaffolded and possibly extended affects is an interesting topic in its own right. Proponents of TAS can, however, remain neutral about the question of extension while maintaining that affective experience is fundamentally enabled and supported by the environment. Since TAS can be assessed independently on its own grounds, I will not discuss the case for extended affectivity any further in this article.

\section{The conceptual boundaries of affective scaffolding}

As noted above, TAS is a relatively recent development in affectivity research. Its fundaments have been discussed most comprehensively by Giovanna Colombetti and Joel Krueger in their article Scaffoldings of the affective mind (2015). Building on the notions of situatedness and niche construction, the authors highlight two basic characteristics of affective scaffolding: active manipulation of the world and mutual influence between agent and environment. More specifically, they emphasize a) the extent to which affective experience involves "actively modifying one's environment for the sake of one's affective life itself", and b) how this leads to the existence of "affective niches", that is, "instances of organism-environment couplings (mutual influences) that enable the realization of specific affective states" (p. 1160). In sum, understanding affective experience requires us to examine "the ways in which agents engineer their affective environments - that is, create affective niches - and in so doing let these environments influence their affective states in an ongoing way" (p. 1160).

From here Colombetti and Krueger proceed to a more specific analysis of affective scaffolding - largely in terms of the aforementioned dimensions (Part 1), including 
structure, temporality, trust, individuality/collectivity, individualization/entrenchment, and conscious intent. The overall result is a rich and nuanced account of the affectively scaffolded mind. That said, I will set aside the details of their multidimensional analysis and focus instead on the two underlying premises of active environmental modification and mutual influence/coupling. This will serve best in assessing the current conceptual boundaries of affective scaffolding.

Let us begin by examining the authors' examples of affective scaffolding. Some of the given cases instantiate activeness and mutuality in straightforward fashion. For instance, when a musician plays an instrument to regulate her ongoing affective state, her experience is patently supported by causally bi-directional environmental interaction (Colombetti \& Krueger, 2015, p. 1164). Other examples, however, exhibit looser notions of activeness and mutuality, such as taking Prozac for depression, going to the movies to be entertained, and choosing soft items of clothing to feel safe and cozy (p. 1162, 1163). Here the agent's activity is limited to merely selecting a resource that then affects her experience with little or no subsequent reciprocity (p. 1163; see also Colombetti, 2017b). Simply put, apart from choosing the resource, the agent is more or less passive and the causal influence unidirectional.

In still other cases, the activity of niche construction is itself portrayed somewhat vaguely. Consider the example of taking a vacation to cheer oneself up (Colombetti and Krueger, 2015, p. 1162). In effect, vacations are extended sequences of events that involve countless interactions with various things in numerous different settings. It is therefore difficult to discern what the constructed niche is and how it involves organismenvironment coupling. What, precisely, is the agent coupled with here? To complicate the matter further, we can transpose the vacation example to other areas of life and ask, for instance, whether going to work each day also qualifies as affective scaffolding - insofar as it provides a sustained sense of accomplishment and security. On the whole, the aforementioned examples indicate that "active environmental modification" and "mutual influence/coupling" have been applied somewhat broadly in conceptualizing the nature and range of affective scaffolding.

This indefiniteness becomes even more apparent if we presume that affects can be scaffolded without individual awareness and, moreover, by way of others' intents and actions, both past and present (Colombetti \& Krueger, 2015; Slaby, 2016; Krueger, forthcoming). For instance, Colombetti and Krueger note how religious and spiritual spaces are often "designed to induce a variety of feelings, such as faith, hope, awe, love, compassion, and guilt, with the aid of disparate material objects and practices" (2015, p. 1171-1172). Such niches tend to develop and operate intergenerationally, "leading to culturally and socially different affective experiences and modalities of conduct" (p. 1172). These observations can be readily applied to the effects of the human-built environment at large, including shopping malls, museums, airports, office spaces, apartment buildings, bars, parks, sporting arenas, and so on. Furthermore, we might consider the effect of human activity on the natural environment as well, for instance in terms of global warming, and examine how this likewise loops back to influence our ongoing experience. Altogether, these 
considerations imply that we are oblivious not only to a notable proportion of our own scaffolding activities, but also to all manner of extra-individually constructed niches that function more or less inconspicuously to structure our experience. It thus seems that, more often than not, we find ourselves in niches that scaffold the way we feel.

One concern regarding such omnipresent and extraneously ordered scaffolding is that it becomes uncertain to whom the prerequisite active environmental modification is, or should be, attributed: to the agent(s) whose feelings are currently being scaffolded, to those who originally constructed the niche, to those who modified it later, or to some or all of the aforementioned collectively and in different points in time? Crucially, it is unclear whether these scaffoldings require any kind of active niche construction from the scaffolded individuals themselves. An attendant issue is that, if we decide to assign the necessary activeness to someone or something other than the agent whose affect is being scaffolded, the matter of mutuality is also obfuscated. Consider Krueger's extreme example of weaponizing music for the purposes of torture. He suggests that in this case the tortured person's affective experience is scaffolded by a hostile musically extended system that removes individual consent and agency altogether (Krueger, forthcoming). If the scaffolded individual loses her ability to actively regulate the ongoing scaffolding process, between whom and what does the relevant organism-environment coupling then occur? How does the tortured person influence the music-as-weapon, that is, that which effectively causes and sustains her current affective state? In sum, it seems that here the prerequisites of active agentic modification and mutual influence are curtailed to the point of non-existence.

This kind of indefiniteness gives rise to a critical concern: What, exactly, counts as affective niche construction and, accordingly, as scaffolded affect? This is not an entirely novel worry. Jan Slaby (2016), for instance, has flagged the lack of distinctive criteria in Colombetti and Krueger's analysis as a potential problem. He notes that "such a broad array of examples might raise doubts: If just any odd affect-inducing object were an instance of affective scaffolding, the proposal would be vacuous" (p. 4). However, having acknowledged this, Slaby gives a rather hasty interpretation of the situation. On his view, "trust, entrenchment and individualization are the criteria discussed by Colombetti and Krueger that distinguish occasional affect inducers from those sustained and regular ones that deserve to be called 'affective scaffolds"' (p. 5). I find this conclusion unwarranted. Colombetti and Krueger do not present the aforementioned features as necessary preconditions for scaffolded affects. Rather, they discuss them as dimensions along which the scaffolded mind varies. Indeed, on their view scaffolded affects do not need to involve trust, entrenchment, and individualization. Nor do they have to be sustained and regular, as Slaby presumes. To return to a familiar example, Colombetti and Krueger note how "the occasional vacation may act as an affective scaffold by cheering us up without being regularly relied upon for regulating our mood" (p. 1162). This and other "one-off" scaffoldings indicate that Colombetti and Krueger do not consider trust, entrenchment, individualization, and regularity as decisive criteria (see also Colombetti, 2017b).

Elsewhere, Krueger (2018) recognizes the problem of indefiniteness and suggests that mutual influence could provide the solution. He writes: 
"Not every environmental interaction supports SA [scaffolded affectivity]. It's unclear that simply coming home and lighting candles to relax after a stressful day scaffolds my affective state in the relevant sense. The causal relation here seems unidirectional: from world (i.e., candles) to me. The soothing light of the candles may help shape my mood. But my affective response doesn't affect a material change in the candles - $a$ bidirectional interplay SA proponents argue is necessary for genuine integration with external resources to occur." (Krueger, 2018, p. 2, my italics.) ${ }^{3}$

Here Krueger quite plainly affirms that affective scaffolding requires causal bidirectionality. That is, the affective response enabled by the resource must also effect a relevant change in the resource itself. But if that is the case, we may wonder how lighting a candle to soothe oneself differs, in terms of mutual influence and proper integration/coupling, from taking Prozac or putting on a bright sweater to regulate one's mood (Colombetti \& Krueger, 2015, p. 1162). If the latter qualify as affective scaffoldings, why doesn't the former? For now, we must make do with the general instructional observation that there are "cases that do involve tight bidirectional engagements, operating both synchronically and diachronically, whereby external resources take over and scaffold regulative dynamics in an ongoing way and, in so doing, open up new forms of experience and expression" (Krueger, 2018, p. 2). This pronouncement sounds valid. However, in light of the discussed examples and considerations, it does not, in effect, currently operate as a compelling distinctive criterion.

As it stands, then, there is an unresolved conceptual ambiguity in TAS. One the one hand, its proponents have conjectured on distinctive criteria for affective scaffolding but, on the other, have not followed up on these provisional suggestions in any systematic or definitive fashion. Some of the discussed examples of affective scaffolding rather seem to undermine the specification of cogent criteria. The overall concern here is that, if we predicate the presuppositions of, for instance, active modification and mutual influence too loosely, the concept of affective scaffolding cannot achieve the distinctive power presumably expected of it. Indeed, applying these two preconditions in the previously discussed broad senses entails that nearly all environments and nearly all activities within these environments will have some kind of scaffolding effect on affective experience, whether it be enabling, regulating, sustaining, altering, etc. In sum, without sufficiently distinctive criteria, the world appears to be one giant niche with which we (must) constantly interact, in one way or another, and with varying degrees of personal deliberation, self-awareness, and control, to influence our affective experience. Simply put, the majority of our affects turn out to be environmentally scaffolded. This theoretical stance has not, however, been explicitly identified as a central tenet or desirable outcome of TAS. It is instead a position that we

\footnotetext{
${ }^{3}$ Interestingly, Krueger and Szanto (2016, p. 867) use the same candle-example and the criterion of bi-directional coupling and integration to distinguish extended affects from nonextended ones. "Mutual influence" is thus used as a distinctive criterion in two different directions, as it were: between extended affectivity and non-extended affectivity and scaffolded affectivity and non-scaffolded affectivity. This complicates the issue further, since it seems to conflate extension and scaffolding.
} 
presently find ourselves in - and one that needs to be assessed directly in order to clarify theorization on the matter. To that end, I next examine possible responses to the situation.

\section{Addressing the challenge of conceptual ambiguity}

Put broadly, we have two options for addressing the ambiguity identified in TAS. The first, restrictive option is to keep pushing for more definite criteria. Ideally, TAS would then provide a clearer differentiation between scaffolded and non-scaffolded affects while considerably limiting the range of the former. Needless to say, pursuing this option presupposes that the concept of affective scaffolding should, by its very nature, enable substantial distinctions. It is only by reason of this expectation that we can judge the concept to be vague and excessively inclusive and can hence motivate the search for more stringent criteria. The second, permissive option would take us in the opposite direction to argue that, by and large, affectivity is indeed scaffolded. Thus, the term scaffolding would not primarily be expected to distinguish between scaffolded and non-scaffolded states but would instead be used to designate and elaborate on a perpetual feature of affective experience. In doing so, we would work with rather than problematize the broad and inclusive understanding of affective scaffolding. Below, I assess each option in turn.

If we take the first, restrictive path, there are various ways in which we might proceed. I outline just one possible approach: a procedure that combines three strategies to seek a more tenable set of criteria. The first step would be to thoroughly examine prior usage of the concept of scaffolding in philosophy of mind and in other pertinent fields (e.g. developmental psychology) (see Pea, 2004; Sutton, 2016). This would enable the explication of, and commitment to, an explicitly contextualized and firmly rooted view of the essential operative relations between environmental scaffolds and the mind. Such groundwork would ideally provide a definite statement of what scaffolding must $d o$ with regard to the mind in order to qualify as scaffolding. Does it suffice, for instance, for a resource to induce and enable cognition or affect, or does the resource also need to support, sustain, drive, modify, regulate, and/or enhance the target mental state? In sum, the first strategy would be to establish, on the basis of previous conceptual work, a precise and clearly justified account of the essential function(s) of scaffolds in relation to the mind.

With a well-defined basic notion of scaffolding in place, we could then shift our attention to affective scaffolding specifically and apply the strategy of contradistinction. That is, we could try to tease out rudimentary criteria for scaffolded affects by juxtaposing cases of feeling that arguably lack environmental affectedness altogether (e.g. bodily-engendered aches) with limit-cases that involve scaffolding in the fundamental sense specified in the first step. Although this would initially amount to rather inclusionary criteria for affective scaffolding, it would also spell out which kinds of affects do not under any circumstances count as scaffolded.

Finally, we could continue to narrow down the category of scaffolded affects by trying out any number of further criteria. One viable option would be to weigh up some of the 
suggestions that have been floated in existing discussions on affective scaffolding. For example, we could, as Krueger indicates $(2018$, p. 2), work towards a sufficiently clear-cut differentiation between a) feelings that are enabled and supported by active environmental manipulation and robust bi-directionality, and b) feelings that simply arise from more passive and unidirectional dealings with one's surroundings. The critical challenge would again be to define the chosen criteria with precision: if, perchance, we were to decide on mutual influence/coupling, more work would be needed to specify what constitutes the relevant kind of bi-directionality and to designate between whom or what, and on what kinds of timescales, these bi-directional interactions must then occur. Moreover, if we were to stipulate strict conditions of reciprocity, activeness, regularity, or something else, we would also need to justify the considerable restrictions this would place on affective scaffolding vis-à-vis prior, broader conceptualizations of the scaffolded mind. In the end, where the line is drawn is of course conditional and contractual. However, that line would be clear and evident to all, and would thus mark a common point of reference for further debate on the topic.

The second, more permissive option for addressing the ambiguity of TAS is to question the very premises that engender this ambiguity. Specifically, we might take issue with the (implicit) supposition that the mind is primarily non-scaffolded and therefore only intermittently reliant on environmental resources for its workings. This approach could draw, for example, from Slaby's (2016) critique of the so-called user/resource model, which, on his view, dominates current theorization of the situated mind. As he puts it, the "baseline mentality in many of the example cases under discussion is that of a fully conscious individual cognizer ('user') who sets about pursuing a well-defined task through intentional employment of a piece of equipment or exploitation of an environmental structure ('resource')" (p. 5). Slaby argues that focusing on such user-driven operative processes sidelines the mind's normative dimension, namely, the fundamental way in which "complex socio-normative patterns enable and constrain individual mental states" (p. 6). He also points out that, if we are "inclined to understand the mind in terms of operative processes alone, it can seem natural to think of it in terms of an individual's inbuilt mental capacities being materially augmented, scaffolded, or extended by some environmental resource" (p. 6). This in turn can easily lead us to adopt something resembling the limited user/resource model. As a countermeasure, Slaby advances an "outside-in model of situated affectivity" that prioritizes "affective subjectification", that is, the way in which "individual subjectivity is continuously shaped by environmental structures, practices, machinery, norms and institutions" (p. 7). From this perspective, our feelings are often invaded and hacked, as it were, from the outside (pp. 7-10).

It should be noted that Slaby does not rely principally on the concept of scaffolding to develop his view of affective subjectification and socially driven affective modulation. Instead, he presents the bulk of his account within the more general framework of situated affectivity. It would therefore be ill-advised to draw any overreaching conclusions as to how pervasive Slaby considers affective scaffolding to be. That said, he does use Colombetti and Krueger's theorization on scaffolding to motivate his own view. He maintains that, by foregrounding "individual intentions and individual comportment", their 
examples of affective scaffolding tend to "gravitate towards" the user/resource model - even if their overall analysis is, in principle, "conducive to a structural reading" that acknowledges the broader social-political milieu (2016, p. 6). Moreover, Slaby suggests that his examination of distributed, outside-in affective structures can help to "render more concrete the notions of an 'affective niche' and of 'affective scaffolding' as invoked by Colombetti and Krueger" (p. 8). All in all, then, Slaby's account of affective subjectification could serve to buttress the claim that feeling is continuously and extensively scaffolded from without and often against individual intentions and orientations altogether. Crucially, this approach erodes the rationale for tightening the range of scaffolded affectivity, especially on grounds of individual activeness and robust agent-environment bi-directionality.

John Sutton has also challenged the notion of a bare, primarily non-scaffolded mind:

"For the sciences of the mind there is no reason to think that the essential level of analysis should be the performance of the naked brain or the unscaffolded mind. Rather, human psychology is most characteristically seen and experienced in our tangled, dynamic interrelations with social, environmental, and technological systems. Instead of stripping away the scaffolding and the multiple influences in search of something pristine beneath, the explanatory task is to document and trace the many forms of scaffolding and the shifting cognitive constructions they support." (Sutton, 2016, p. 197.)

This is a much more far-reaching position than to assume that we sometimes interact with the environment in order to scaffold our minds. It suggests that the mind is always already entangled in, and supported by, a dense web of scaffoldings. Referring specifically to affect, Sutton notes how "our moods and emotions are constantly shaped, given precision or flavor, by way of social uptake, culturally-specific caring practices, or selfinduced rituals and habits such as listening to music, going to a particular place, or just having another coffee" (2016, p. xx). In sum, his view highlights how common yet multiform affective scaffolding really is.

From this broader perspective, Sutton, like Slaby, throws into doubt the need for more restrictive criteria for affective scaffolding. He advises us to continue using the concept productively to identify and analyze, within a multidimensional framework, the various ways, forms, and situations in which experience is environmentally supported (see Sutton, 2016; Sutton et al., 2010). On this account, feeling would in some cases turn out to be scaffolded bi-directionally, while in others, uni-directionally or perhaps even multidirectionally; in some cases, with conscious individual intent and control, and in others, completely from without; in some cases, synchronically, in others, diachronically, and in still others, on both temporal levels - and so on in numerous different variations. Following Sutton, "a science of the scaffolded mind" would thus "operate across all of these levels, types, and timescales of scaffolding" (2016, p. 194-195). 
All things considered, I find the latter, permissive approach more pragmatic and productive than the restrictive one. Instead of grappling with the seemingly insoluble dilemma of definite criteria, it enables us to apply the concept of affective scaffolding more freely and flexibly. It puts us in a position to assess, in any given instance, whether or not the concept succeeds in revealing anything new and noteworthy about the relations between the environment and the feeling individual. Simply put, we can test drive the concept from case to case to see what the pay-off is. Some applications will no doubt turn out to be largely trivial. For example, taking a hot shower to relax, walking by the lakeside to find oneself calmed by the ambience, and inducing a neck pain by sitting endlessly at the computer all instantiate, in a broad sense, environmental interactions that induce and support certain feelings. They may thus be designated as cases of affective scaffolding. That said, we could easily pile up similar examples and soon lose interest in the whole affair. Such employment of the concept merely serves to illustrate the general notion that, on the permissive view, the world is indeed a multileveled affective niche with which we constantly interact to influence our feelings. Here the concept arguably does little to deepen our understanding of the various ways in which environmental elements are manipulated, by ourselves and by others, to prop up our affective states. Arguably, we might just as well manage without it.

I maintain that the concept of scaffolding is applied productively to affectivity when a) it is clearly positioned vis-à-vis prior, apposite conceptualizations, b) it reveals something new and significant about the way in which affective experience is supported by the environment, and c) it enables us to expand on this revelation in a rigorous, comprehensive, and illuminating way. Obviously, there are no absolute measures for novelty and relevance; these are matters of continuing discussion and evaluation, as they should be. However, this is where the multidimensional framework, as outlined in Part 1, serves a pivotal function. That is, an enriching analysis can be expected to examine scaffolded affect in terms of structure, temporality, reciprocality, trust, individuality/collectivity, individualization/entrenchment, conscious intent, and personal control/consent. In short, it should provide a nuanced and extensive explication of the relations between the environment and the specified scaffolded affect.

Based on the multidimensional framework, interesting applications of affective scaffolding are set to come in various different forms. Illuminating cases might include, for example, ones which - echoing Slaby's interpretation of Colombetti and Krueger - exhibit high degrees of trust, entrenchment, individualization, and/or regularity; ones which, following Krueger's observations, involve robust bi-directionality between the scaffolded individual and the scaffolding resource; and ones which employ Slaby's own account of affective subjectification to reveal and critique extra-individually manipulated feelings. In this manner, the multidimensional approach enables us to analyze flexibly scaffoldings that depend on user/resource interactions and scaffoldings that are politically, normatively, and even coercively structured from without.

At this stage one might ask: Must not the permissive option also rely on some kind of distinction between scaffolded and non-scaffolded affects? Indeed, it must, but all that is required is a minimal operative demarcation. We may, for instance, work with the 
following basic definition: affective scaffolding occurs when the environment is manipulated by an individual, or by others, to support, synchronically or diachronically, that individual's ongoing affective experience, wherein "environment", "manipulation", and "support" are construed as broadly as possible. As suggested, this leads to the view that affectivity is more or less constantly scaffolded, which in turn eliminates the need for further distinctive criteria. From this starting point, we may then proceed to explore within the multidimensional framework those instances of affective scaffolding that merit closer scrutiny.

\section{Conclusion}

In this article, I have discussed a neglected conceptual tension at the heart of TAS. Advocates of affective scaffolding have made several suggestive observations about the necessary features of affective scaffoldings - most prominently in terms of active environmental modification and mutual influence. However, these remarks have not been developed into fully-fledged distinctive criteria. This gives rise to uncertainty over the theoretical functions of the concept of affective scaffolding. To address this ambiguity, I have outlined two elucidatory options. The first, restrictive option is to keep pushing, via several methodical steps, for more definite and limiting criteria. The second, permissive option is to embrace and work with a broad understanding of affective scaffolding. I have suggested that the latter option is preferable, since it eradicates the need for stricter distinctive criteria and allows us to apply the concept more flexibly from case to case in order to assess its explanatory and descriptive value. Combined with tools from a multidimensional view of the scaffolded mind, the permissive approach enables productive and enriching analyses of affective scaffolding.

To be clear, my examination has not been intended as a takedown of prior theorization on affective scaffolding. On the contrary, its aim has been to build on the vitally important groundwork done by Colombetti, Krueger, Slaby, and others. As mentioned, TAS is still in a preliminary stage of development. It is to be expected, then, that some of its ideas will be rough around the edges. I have identified and analyzed just one insufficiently discussed issue: how current ambiguity over distinctive criteria causes uncertainty about the use of "affective scaffolding". Again, by suggesting constructive alternatives to address the matter, I have not aimed to negate Colombetti and Krueger's analysis of the affectively scaffolded mind. Instead, I hope to have presented tools that can serve to clarify the premises and theoretical commitments that underlie it. All in all, based on the above discussion, I maintain that there are two key questions that any cogent analysis of affective scaffolding should address directly. First, what constitutes scaffolding in its basic, minimal sense, and second, to what extent is the mind inherently scaffolded? The answers to these questions bear decisively on what we can, and should, expect the concept of affective scaffolding to do for us. 


\section{References}

Clark, A. (1997). Being there: putting brain, body, and world together again. Cambridge, MA: MIT Press.

Clark, A. (2006). Language, embodiment, and the cognitive niche. Trends in Cognitive Sciences, 10(8), 370-374.

Colombetti, G. (2017a). Enactive affectivity, extended. Topoi, 36 (3), 445-455.

Colombetti, G. (2017b). The embodied and situated nature of moods. Philosophia, 45: 1437. Online first https://doi.org/10.1007/s11406-017-9817-0.

Colombetti, G. \& Krueger, J. (2015). Scaffoldings of the affective mind. Philosophical Psychology, 28 (8), 1157-1176.

Colombetti, G. \& Roberts, T. (2015). Extending the extended mind: the case for extended affectivity. Philosophical Studies, 172, 1243-1263.

Griffiths, P. E. \& Scarantino, A. (2009). Emotions in the wild. In P. Robbins \& M. Aydede (Eds.), The Cambridge handbook of situated cognition (pp. 437-453). Cambridge: Cambridge University Press.

Heersmink, R. \& Sutton, J. (2018). Cognition and the Web: extended, transactive, or scaffolded? Erkenntnis. Online first: https://doi.org/10.1007/s10670-018-0022.

Krueger, J. (2014a). Emotions and the social niche. In C. von Scheve \& M. Salmela (Eds.), Collective Emotions (pp. 156-171). Oxford: Oxford University Press.

Krueger, J. (2014b). Varieties of extended emotions. Phenomenology and the Cognitive Sciences, 13, 533-555.

Krueger, J. (2018). Schizophrenia and the scaffolded self. Topoi. Online first: https://doi.org/10.1007/s11245-018-9547-3

Krueger, J. (forthcoming). Music as affective scaffolding. In D. Clarke, R. Herbert, \& E. Clarke (Eds.), Music and Consciousness II. Oxford: Oxford University Press.

Krueger, J. \& Szanto, T. (2016). Extended emotions. Philosophy Compass, 11, 863-878.

Laland, K., Matthews, B., \& Feldman, M. W. (2016). An introduction to niche construction theory. Evolutionary Ecology, 30 (2), 191-202.

Maiese, M. (2016). Affective scaffolds, expressive arts, and cognition. Frontiers in Psychology, 7: 359.

Merleau-Ponty, M. (1962). Phenomenology of perception (Trans. C. Smith). New York: Routledge. 
Odling-Smee, F. J., Laland, K. N., \& Feldman, M. W. (2003). Niche Construction: The Neglected Process in Evolution. Princeton, NJ: Princeton University Press.

Pea, R. D. (2004). The social and technological dimensions of scaffolding and related theoretical concepts for learning, education, and human activity. Journal of the Learning Sciences, 13 (3), 423-451.

Robbins, P. \& Aydede, M. (2009). A Short primer on situated cognition. In P. Robbins \& M. Aydede (Eds.), The Cambridge handbook of situated cognition (pp. 3-10). Cambridge: Cambridge University Press.

Saarinen, J. A. (in press). Paintings as solid affective scaffolds. Journal of Aesthetics and Art Criticism.

Scott-Phillips, T. C., Laland, K.N., Shuker, D. M., Dickins, T. E., \& West, S. A. (2014). The niche construction perspective: a critical appraisal. Evolution, 68 (5), 1231-1243.

Slaby, J. (2014). Emotions and the extended mind. In C. von Scheve \& M. Salmela (Eds.), Collective Emotions (pp. 32-46). Oxford: Oxford University Press.

Slaby, J. (2016). Mind invasion: situated affectivity and the corporate life hack." Frontiers in Psychology, 7: 266.

Slaby, J., Mühlhoff, R., \& Wüschner, P. (2017). Affective arrangements. Emotion Review.

Stephan, A., Walter, S. \& Wilutzky, W. (2014). Emotions beyond brain and body. Philosophical Psychology, 27, 65-81.

Sterelny, K. (2010). Minds: Extended or scaffolded? Phenomenology and the Cognitive Sciences, 9(4), 465-481.

Sutton, J. (2016). Scaffolding memory: themes, taxonomies, puzzles. In Charles Stone \& Lucas Bietti (Eds.), Contextualizing Human Memory: An Interdisciplinary Approach to Understanding how Individuals and Groups Remember the Past, (pp. 187-205). New York: Routledge.

Sutton, J., Harris, C. B., Keil, P. G., \& Barnier, A. J. (2010). The psychology of memory, extended cognition, and socially distributed remembering. Phenomenology and the Cognitive Sciences, 9 (4), 521-560.

Wilson, R., \& Clark, A. (2009). How to situate cognition: Letting nature take its course. In P. Robbins \& M. Aydede (Eds.), The Cambridge handbook of situated cognition (pp. 55-77). Cambridge: Cambridge University Press. 